\title{
Sciendo
}

\section{Directions for improving the quality of education in Belarusian universities (sociological analysis)}

\author{
Yury Kalesnik \\ Sukhoi State Technical University of Gomel (Belarus) \\ Email:kolesnik@gstu.by \\ Vadzim Kleiman \\ Sukhoi State Technical University of Gomel (Belarus) \\ Email:kleiman_vadim@mail.ru \\ Valentina Vasicheva \\ Linnaeus University (Sweden) \\ Email:valentina.vasicheva@Inu.se
}

Doi: $10.2478 /$ gssfj-2020-0004

\begin{abstract}
Educational institutions all over the world realize the importance of promoting international cooperation. In order to stay competitive in such fields like education, research, innovations it is no longer enough to count on only internal resources. Exchange of experience, knowledge sharing, benchmarking provide possibilities for universities to constantly remain updated on modern know-hows.

New opportunities for improving the quality of higher education in Belarus are provided by different international programs and projects. Among them there is the project of the EU Program ERASMUS + CBHE "University Teaching and Learning Enhancement" / UniTeLE, which has been implemented since 2019. The project coordinator is Linnaeus University (Sweden).

In the framework of the ERASMUS + UniTeLE project, a consortium of Belarusian universities has conducted a bigher education quality research. The purpose of this research is to identify areas for improving the quality of higher education in Belarus.

The research was carried out on the basis of a sociological survey of a representative sampling of teachers, staff and students of six Belarusian universities (more than 350 respondents from Minsk, Gomel, Brest, Gorki, Polotsk, Grodno were interviewed). Both SWOT analysis of higher education quality in Belarus and focus group of possible improvement were performed. The discussion was attended by work groups of 25 leaders, teachers and students from each of the Belarusian universities of the project consortium.

The following fundamental research results should be noted. Among the strengths of Belarusian universities are: specialization in the regions, the system of additional adult education, and practical experience of teachers (2/3 of respondents). $58 \%$ of respondents are confident in the advantages of innovative educational technologies used by teachers, $47 \%$ indicated a low intensity of innovation implementation. Respondents noted the high level of Hard Skills competencies of the teaching staff and insufficiently of Soft Skills competencies for both teachers and students. The respondents identified outdated educational technologies and methods and the content of curricula as the fundamental weakness of Belarusian education.

The following areas of quality improvement have been identified as the most important for Belarusian universities:

- the development of Soft Skills competencies of both teachers and students to provide their close interaction;

- the development of Soft Skills competencies among students to provide their close interaction with employers (the development of job search skills, entrepreneurial activity);
\end{abstract}


- the introduction of active teaching and learning methods, the development of interactive educational technologies;

- the inclusion of students in the process of education quality internal assessment;

- systematic assessment of teachers, including the process of applying for a job, teacher academic development planning (HR management).

For the practical improvement in the suggested areas, it is advisable to create Life Long Learning Centres and Centres of Academic Development of teachers in Belarusian universities, as well as a student-oriented quality assessment system. To improve the quality and competitiveness of Belarusian education, it is also advisable to develop international cooperation and networking among universities. The positive experience of such projects as TEMPUS ECOTESY, ERASMUS + UniTeLE, ERASMUS + BELL and others, can contribute to such cooperation and interaction.

Key words: academic development, education quality, active learning, network interaction, soft skills.

\section{Introduction}

There is no doubt about the global impact of the quality movement. In the development of most sectors (e.g. education, health-care, trade, services, manufacturing, etc.), worldwide economic integration and the growth of the global market, quality becomes one of the main factors of organizational competition and success. In higher education sectors nowadays there are problems of structure, personalities, students, academic staff, university staff and management. All this creates a complex situation in which higher education must be assessed (Zineldin, Akdag, Vasicheva, 2011). According to Hofstede (1982), quality should be embedded in the culture of organisations. Therefore, it is vital to establish and implement quality assurance strategies which are imbedded into all university services. As higher education institutions are recognizing that higher education is not only a service industry, but also a place where knowledge is 'made', preserved; a critical thinking place reflecting on society, etc. Involving students in course design, development and evaluation provides instructors with great understanding and direct insight into relevant issues of student learning and knowledge management (Gapp and Fisher, 2006). Belarusian higher education needs quick response mechanisms to changing business needs, to the development of new professions and activities. Today, Belarusians are interested in modern educational technologies for the rapid development of new competencies, lifelong learning with maximum in-service training. Improving the quality of higher education is especially relevant in the face of new challenges of the time (such as, for example, COVID-19). Such challenges require the transformation of educational processes.

The development of connections with the largest universities of the European Union, including such ways as international programs and projects, helps to improve the quality of Belarusian higher education. International projects allow to consolidate the efforts of the best scientists and practitioners of European countries for the development of educational technologies and 
teaching methods. The positive experience of such projects as TEMPUS ECOTESY, ERASMUS + UniTeLE, ERASMUS + BELL and others, can contribute to this cooperation and interaction (Kalesnik and Uzunos, 2019) Thus, new opportunities are provided by the international project of the EU ERASMUS + CBHE Program "University Teaching and Learning Enhancement" / UniTeLE (hereinafter referred to as "UniTeLE"), which has been implemented since 2019. The project coordinator is Linnaeus University (Sweden).

The members of the UniTeLE consortium are Linnaeus University (Sweden), University of Genoa (Italy), Heidelberg University of Education (Germany), Nevsehir Haci Bektas Veli University (Turkey) and the following Belarussian universities: BSU (Minsk), PSU (Polotsk, Vitebsk region), GSTU (Gomel), YKSUG (Grodno), BSAA (Gorki, Mogilev region), BrSTU (Brest).

The wider objective of this project is development of an internal Quality Assurance (QA) system at Belarusian (BY) partner universities for their academic development with in-service teacher-training programme for structural improvement of the employment and pedagogical performance of teaching staff and students' participation in quality assurance at BY Universities.

To achieve the goal of the UniTeLE project, a consortium of Belarusian universities carried out a Particularisation of Intervention Areas research, including:

- $\quad$ SWOT analysis of QA at each BY partner;

- Definition of areas of concern \& project intervention.

The research concept was developed at a kick-off meeting at Linnaeus University, Sweden. It is based on a questionnaire survey and interviewing of the expert community, stakeholders, focus group analysis of the quality of higher education processes and its development priorities.

In accordance with the main working hypothesis of the UniTeLE project, higher education system should be student-centreed. Thus, student's needs and capabilities become the basis for the university management. The authors of this article have proposed a joint research algorithm that includes the following 7 main stages: 


\begin{tabular}{|c|c|}
\hline $\begin{array}{l}\text { Steps of the joint } \\
\text { research }\end{array}$ & The direction of the joint research \\
\hline STEP 1 & Development of a unified approach to research \\
\hline STEP 2 & $\begin{array}{l}\text { Creation of working Groups in each of the } 6 \text { Belarusian } \\
\text { universities of the project consortium: } 10+\text { managers, } \\
15+\text { teachers. }\end{array}$ \\
\hline STEP 3 & $\begin{array}{l}\text { Carrying out at each university sociological research by } \\
\text { questioning managers, teachers, students, alumni (at least } \\
500 \text { respondents). }\end{array}$ \\
\hline STEP 4 & Sociological analysis of the survey results. \\
\hline STEP 5 & $\begin{array}{l}\text { Conducting focus groups at universities in areas of } \\
\text { improving the quality of Belarusian higher education. } \\
\text { Participants: managers, teachers, students. }\end{array}$ \\
\hline STEP 6 & $\begin{array}{l}\text { Preparation of summary report: the matrix of the } \\
\text { SWOT-analysis of quality of higher education. }\end{array}$ \\
\hline STEP 7 & $\begin{array}{l}\text { Defining Interventions and Improvements: SWOT } \\
\text { Offerings Matrix. }\end{array}$ \\
\hline
\end{tabular}

Table 1 -Research stages «Particularisation of Intervention Areas»

The proposed algorithm provided:

- creation of inter-university expert groups consisting of more than 60 managers and more than 90 teachers from six Belarusian universities;

- participation in a sociological survey of more than 350 students and graduates of Belarusian universities located in Minsk, as well as in regional and district centres;

- representative sample balanced by gender, age, social and professional status.

The main methodological tool of sociological research proposed by the authors is questionnaire. It contains 27 basic and 4 additional questions. Questions and answer options allow to reveal the opinion of respondents about the problems of higher education and the factors that determine its quality. The questionnaire embraces the following areas:

- professional skills as well as social and personal skills, including experience, reputation, qualifications, continuous training and skills upgrading, motivation;

- condition of university material and technical base (classroom quantity and quality, equipment, laboratories, physical, cultural and intellectual development centres)

- applied educational technologies, educational and methodological support, training software products, information support;

- university cooperation with stakeholders; 
- peculiarities of both students and teachers' social roles;

- management of students' self-education work

- demographic, economic, political factors impact on the higher education system;

- international university cooperation impact on the quality of higher education.

Also, the questionnaire included questions aimed at identifying the top characteristics of universities that determine their competitive advantages in the educational services market.

The opinion poll was conducted offline and online in 2019. Over 500 respondents took part in the survey. (Figure 1).

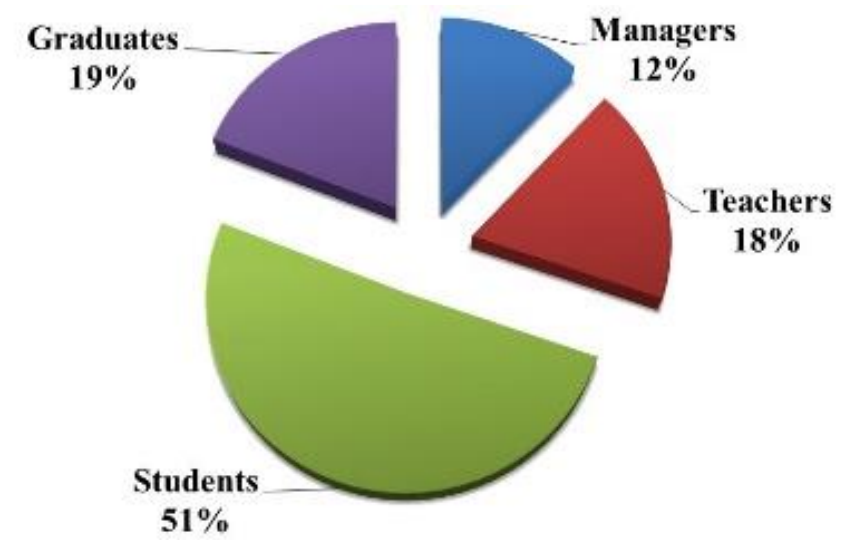

Figure 1 - The structure of participants in a sociological survey

Analysis of the survey results in focus groups allowed us to build a matrix of SWOT-analysis and a matrix of SWOT-proposals for the subject of the study "Particularization of Intervention Areas".

\section{Results of a sociological study on the quality of higher education in Belarusian universities.}

\subsection{Interaction with consumers of educational services}

Based on the results obtained data processing, the strengths and weaknesses of Belarusian universities in the field of the quality of higher education have been identified. The current threats and opportunities appearing due to changes in the external environment have been defined.

Almost two thirds of respondents $(63 \%)$ are sure that the strength of Belarusian higher education is the demand for university graduates in the labor market. This may be the result of good cooperation between educational institutions and enterprises, that can further employ graduates. These enterprises usually take part in the process of the training of specialists and 
then perform as personnel customers $(55 \%$ of respondents indicated this as the advantage).

According to the opinion of the survey participants, constant communication with personnel customer enterprises allows university to respond in a timely manner to changes in the labour market, to introduce new demanded specialties, and to adjust curricula.

A significant influence on improving the quality of education at Belarusian universities is provided by the existing system of additional adult education in Belarus. Today, additional adult education providers are the first to learn about people's needs for specific new knowledge and skills.

The departments of Belarusian universities, which are aimed at upgrading and retraining of personnel for private and public business have become real platforms for the consolidation of experts from the business community, government agencies and competent teaching practitioners. Such cooperation helps to solve problems of improving the education quality in the context of permanent modernization of Belarusian society.

\subsection{The competencies of teachers.}

One more important factor in the success of Belarusian higher education is the competence of teachers. Interviewees noted such advantages of Belarusian teachers as practical experience, the use of innovative technologies, individual work with students and others (Figure 2).

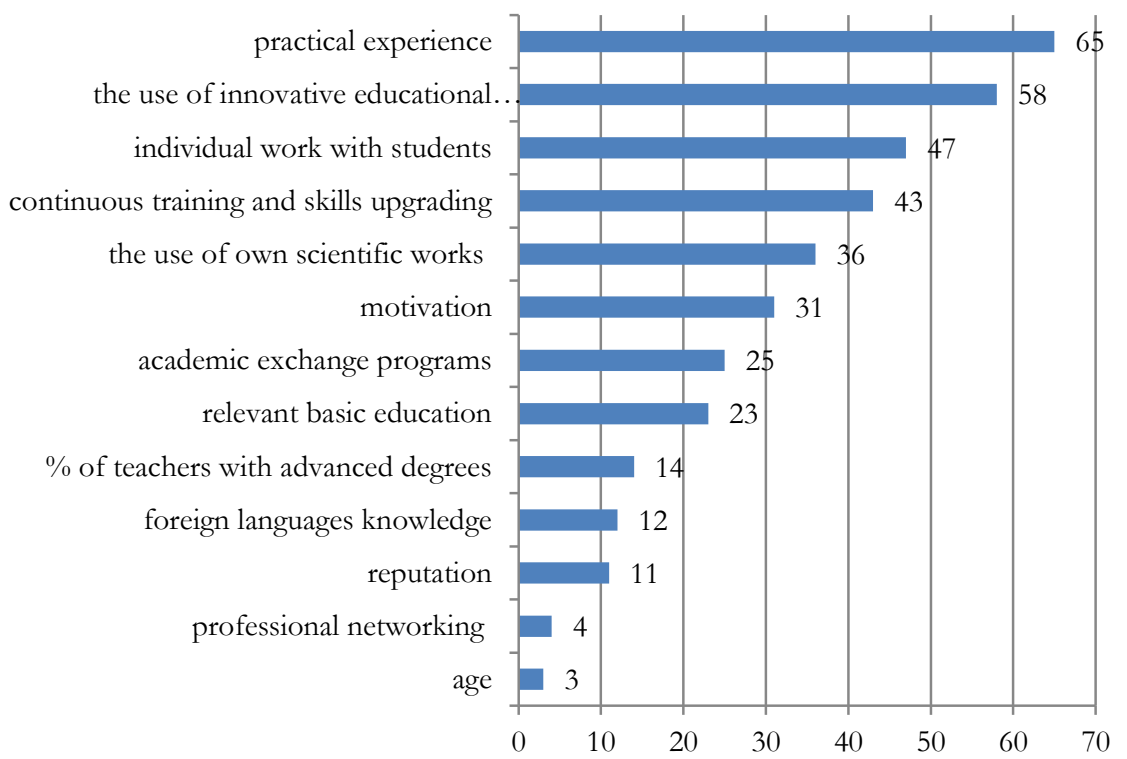

Figure 2 - The range of answers to the question "Indicate what characteristics of university teachers are their strengths (advantage over competitors), that provide high quality teaching" ( $\%$ of respondents chose the option) 
At the same time, the ranking of reasons that reduce the quality of education (Figure 3) has a high intensity of answers "Low motivation among teachers" $(59 \%)$ and "low intensity of the innovative educational technologies introduction" (47\%).

In addition to that, the assessment of the quality of individual work with students is quite ambiguous: $47 \%$ of respondents consider it is as a strong point of Belarusian universities, while $40 \%$ consider it as a weak one.

Respondents noted rather high level of professional competencies of the teaching staff and lack of social and personal competencies for both teachers and students.

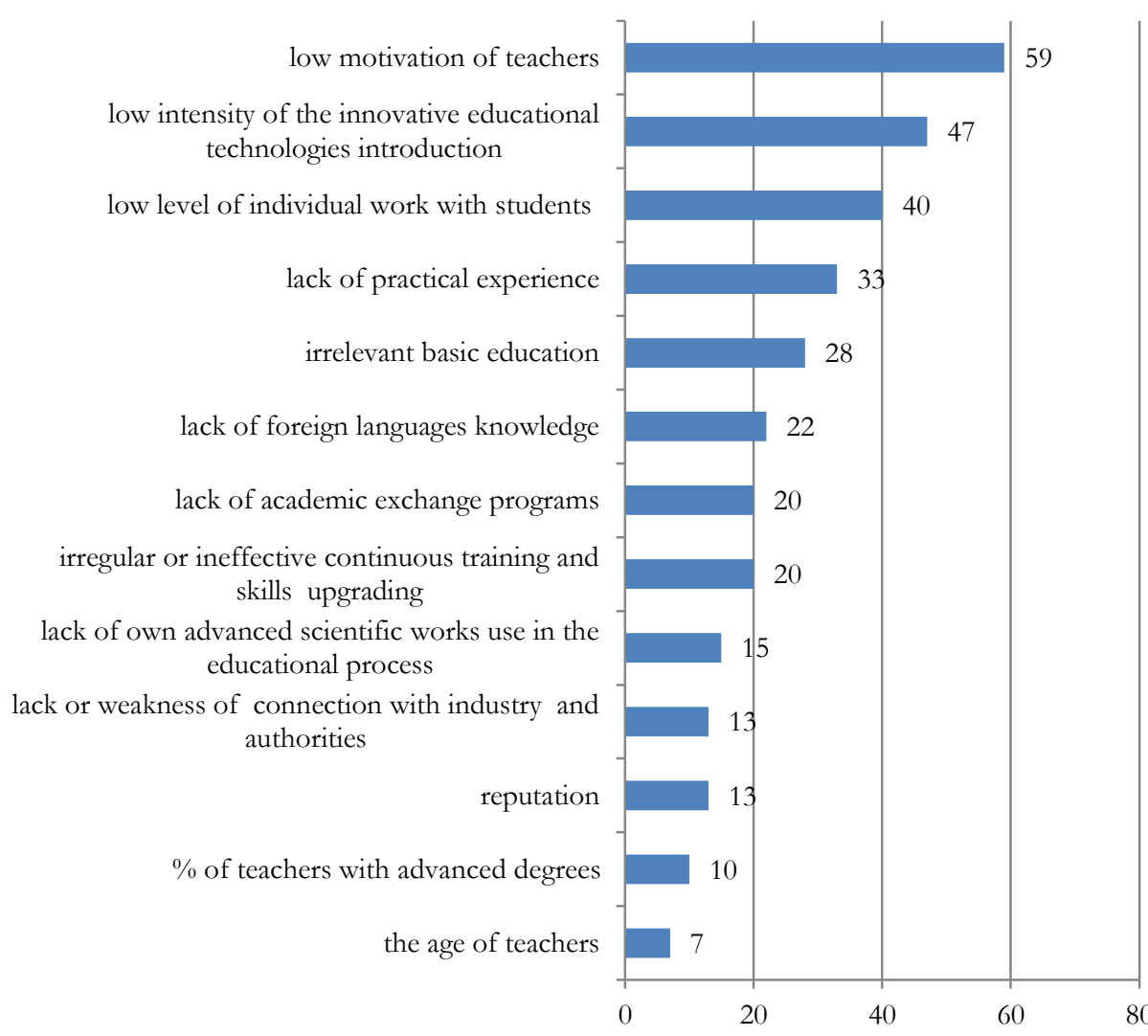

Figure 3 - The range of answers to the question "Indicate what characteristics of university teachers are their weaknesses that reduce the quality of education and teaching" (\% of respondents chose the option)

About $20 \%$ of respondents noted an insufficient level of teachers' pedagogical training, especially in technical universities.

In the TOP of weaknesses, point "low level of foreign languages knowledge by teachers" has also been noted. 


\subsection{Material resources and infrastructure for personal} development.

Respondents identified elements of the material base as significant factors ensuring the strength of the university, its competitiveness (Figures 4 and 5). The competitiveness of Belarusian universities (according to the respondents) is determined primarily by modern equipment $(52 \%)$ and the centres of intellectual development (availability and quality of libraries, scientific sections and laboratories, student science, etc. - 49\%).

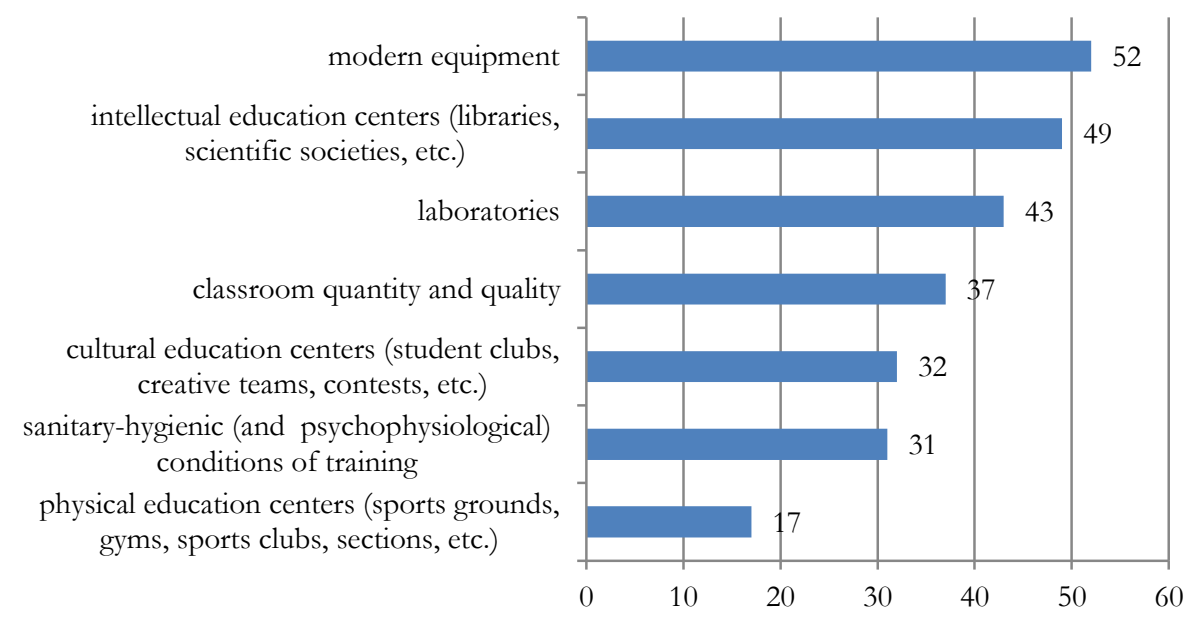

Figure 4 - The range of answers to the question "Indicate what characteristics of the material base of the university are its strength, that provide high quality education and teaching." (\% of respondents chose the option)

The possibility to use the material base of partners (enterprises and organizations personnel customers) increases the efficiency of universities. At the same time, the majority of respondents indicated the necessity to renovate existing laboratories $(58 \%)$ and equipment (55\%), as well as the introduction of modern equipment for new specialties, programs and academic disciplines. 


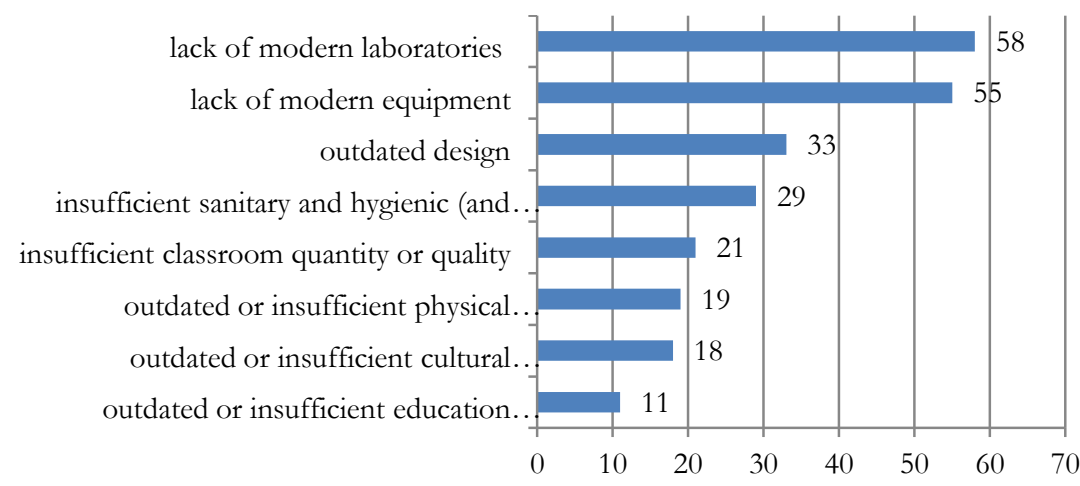

Figure 5 - The range of answers to the question "Indicate what characteristics of the university material base are its weaknesses that reduce the quality of education and teaching." ( $\%$ of respondents chose the option)

The competitiveness of Belarusian universities (according to responses) is formed due to a decent intellectual base (libraries, research laboratories, etc. 49\%).

Also, the competitiveness of Belarusian universities is formed due to cooperation with enterprises, organizations - personnel customers, which allows to use the material and technical base of partners.

At the same time, more than a half of respondents believe that renovation of existing laboratories (58\%) and equipment (55\%), as well as the introduction of modern equipment for new demanded specialties, programs and academic disciplines is required.

\subsection{Intangible assets and educational technologies.}

Less than half of the respondents identified the applied educational technologies, curriculum content, patents and image as university strengths (Figure 6). 


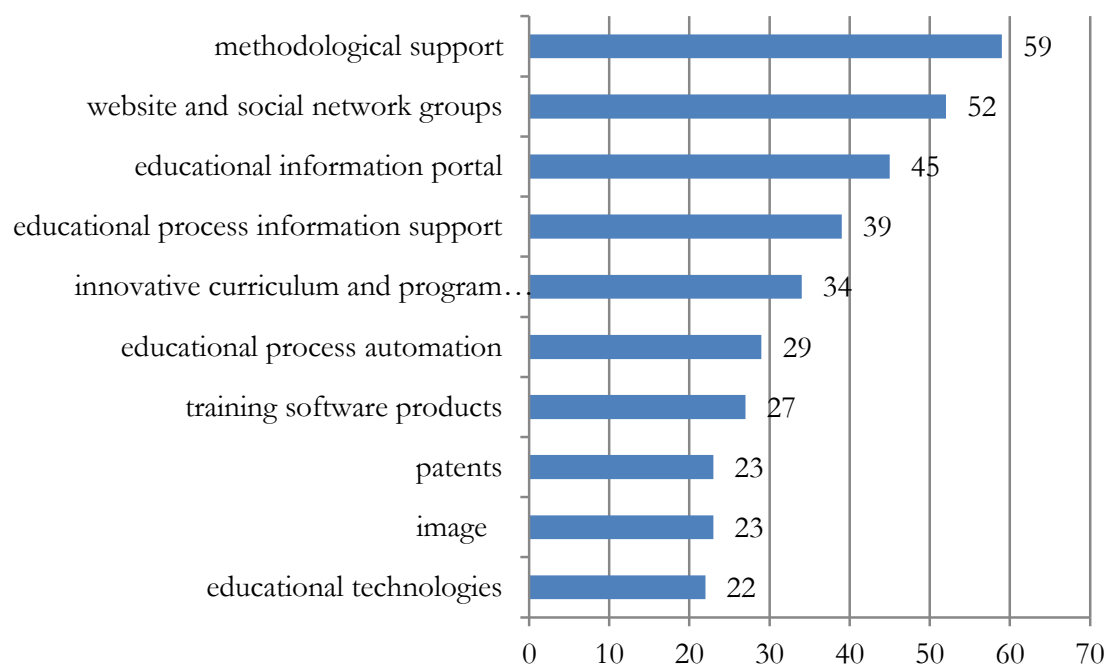

Figure 6 - The range of answers to the question "Indicate what characteristics of non material base of the university are its strength, that provide high quality education and teaching." ( $\%$ of respondents chose the option)

But it is precisely these factors that respondents recognized as essential for the quality of education. And then their condition was evaluated as not good enough, which leads to reduction of Belarusian universities competitiveness (Figure 7).

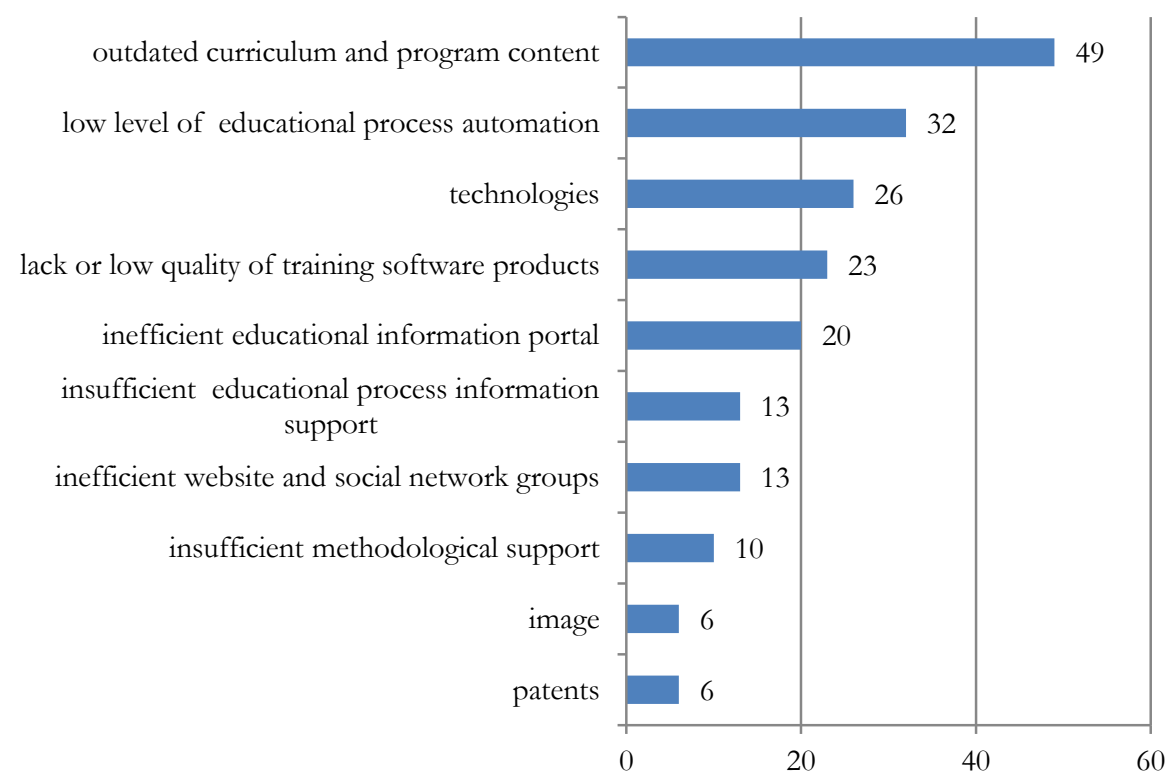

Figure 7 - The range of answers to the question "Indicate what characteristics of the university non-material base are its weaknesses that reduce the quality of education and teaching." (\% of respondents chose the option) 
Informational support of the educational process and providing students with high-speed Internet has been identified by the respondents as important aspects of improving the quality of Belarusian higher education.

Concluding the above-mentioned results, it is necessary to note the following aspects of improving the quality of higher education. It is necessary to intensively introduce innovative educational programs, actively use information and communication educational technologies, and develop interactive, distance forms of higher education.

\section{The results of the quality of higher education discussion in focus groups}

The results of sociological data processing allowed us to identify the main threats to the quality of Belarusian higher education:

- $\quad$ reduction of teachers motivation;

- demographic decline;

- $\quad$ increased workload for the teacher;

- $\quad$ large quantity of unnecessary subjects in higher education;

- the outflow of highly qualified personnel from universities to other areas of management.

At the same time, the prospective for further development of Belarusian higher education are closely connected to intensive cooperation with foreign universities, cooperation with enterprises, academic exchange programs, international educational projects, organization of training in a foreign language, educational services export.

The results of the analysis show that it is necessary to continue the development of innovative infrastructure in Belarusian universities. It is necessary to continue creating the conditions for higher education in demand on the labour market. It is advisable to create and develop:

- science and techno parks, that allow to commercialize student projects

- centres for academic development and teacher training;

- centres for student career development, that allow to form key social and personal competencies and contribute to the professional orientation of students.

It is important to note that the students who are at the centre of the modern system of Belarusian higher education should know the directions of their career development, should acquire necessary key hard skills and soft skills. It is advisable to constantly monitor the quality of the educational process with the participation of all interested, including students. 


\section{Conclusion}

Thus, to improve the quality of Belarusian higher education, a consortium of Belarusian universities participating in the UniTeLE project recommends:

- The development of Soft Skills competencies among teachers (interaction with students, etc.);

- $\quad$ The use of active learning methods;

- The development of Soft Skills competencies among students (skills in job search, entrepreneurship, self-employment, etc.);

- Involvement of all stakeholders, especially students, in the process of education quality insurance;

- Systematic assessment of university teachers;

- The recruitment and academic development of university teachers (HR-management).

The developed methodological base, the system of information support of the educational process, as well as highly qualified teachers who are able to use modern educational technologies and have necessary social and personal competencies, should contribute to the conscious desire of students to master (improve) the key competencies for their future (or present) workplace through Life Long Learning

To improve the quality and competitiveness of Belarusian education, it is also advisable to develop international cooperation and networking among universities.

\section{References}

Gapp, R., and Fisher, R. (2006), Achieving excellence through innovative approaches to student

involvement in course evaluation within the tertiary education sector, Quality Assurance in Education, Vol. 14, No. 2, pp. 156-166

Hofstede, G. (1982), Culture's Consequences - International Differences in Work-Related Values, Sage Publications, London

Kalesnik Y. and Uzunoz F.C. (2019). Analysis of the best practices of universities in European space for the development of educational activities of Belarusian universities / Problems of modern education in a technical university. VI Intern. scientific method. conf., Gomel, October 24-25. 2019 pp.11-20.

Zineldin, M., Akdag, H., \& Vasicheva, V. (2011). Assessing Quality in Higher Education: New Criteria for Evaluating Students' Satisfaction. Quality in Higher Education, 17, pp.231243 